\title{
Current Account Sustainability in the US: What do we really know about it?
}

\author{
Dimitris K. Christopoulos \\ Department of Economic and Regional Development, \\ Panteion University \\ Miguel A. León-Ledesma \\ Department of Economics \\ University of Kent
}

October 2004

\begin{abstract}
We revisit the debate on the sustainability of the current account dynamics in the US. Using the concept of sustainability as the ability to meet the long run intertemporal budget constraint, we test for unit roots in the US current account for the 1960-2004 period. We argue that there are several reasons to believe that the current account may follow a non-linear behavior under the null of stationarity. This is confirmed by a set of non-linearity tests. We then fit an ESTAR model to the current account dynamics and reject the null of non-stationarity. Hence, we conclude in favor of sustainability. Furthermore, our results reveal that only for the period 1974-1992 we can find significant deviations of the current account from equilibrium and a slower speed of mean reversion.
\end{abstract}

JEL classifications: $\mathrm{C} 22, \mathrm{~F} 32$.

Keywords: current account sustainability; stationarity; non-linear models.

Acknowledgements: We would like to thank, without implicating, Alan Carruth, Catharine Mann, Ole Rummel and Adolfo Sachida for their useful comments.

Address for correspondence: Dr. Dimitris K. Christopoulos, Department of Economic and Regional Development, Panteion University Leof. Syngrou 136, 17671, Athens, Greece Tel. +30-210-9224948, Fax: +30-210-9229312, e-mail address: christod@panteion.gr. Miguel A. León-Ledesma, Department of Economics, Keynes College, University of Kent, Canterbury, Kent, CT2 7NP, UK. Phone: +44 (0)1227 823026. Email: m.a.leon-ledesma@kent.ac.uk 


\section{Current Account Sustainability in the US: What do we really know about it?}

\section{Introduction}

The concept of current account sustainability has long been the focus of research and policy debate in economics. The basic idea is appealing as it amounts to analyzing whether a country is able to meet its intertemporal budget constraint in the long-run without incurring episodes of fast and painful adjustment. Long periods of unsustainable current account dynamics may end either abruptly by generating exchange rate crises and output collapse or by achieving a soft landing that will inevitably imply investment and growth slowdowns.

The concept of current account sustainability is linked to the stationarity of the current account balance, as non-stationary dynamics would imply a violation of the inter-temporal budget constraint. Testing for the presence of unit roots and cointegration in the current account dynamics of developed and emerging markets has been the focus of many papers such as Trehan and Walsh (1991), Otto (1992), Wickens and Uctum (1993), Liu and Tanner (1996), Wu (2000) and Taylor (2002). Their results yield mixed results depending on the countries, the sample and the testing procedures considered. As Taylor (2002) points out, the speed of mean reversion of the dynamics of the current account can also be considered as a summary statistic of the degree of capital mobility. This degree of capital mobility is subject to policy and institutional changes.

In the case of the US, the sustainability of the current account has attracted much attention from both academics and policy makers (see, recently, Obstfeld and Rogoff 2004, Mann 2002, Cooper 2001, McKinnon 2001 and Ventura 2001). The increased current account deficits have certainly been a cause of concern. Figure 1 plots the quarterly current account balance to GDP ratio in the US from 1960:1 to $2004: 1{ }^{1}$ It is easy to see that the end of the 1990s and beginning of the 2000s has witnessed levels of deficits previously unseen except for the spell of dollar appreciation in the mideighties. The accumulated current account deficit in 2003 averaged almost 5\% of GDP. This concern is reflected in IMF (2004) who claim that one of the main risks for

\footnotetext{
${ }^{1}$ The data used in this study is from the US Bureau of Economic Analysis.
} 
economic recovery was in "achieving an orderly resolution of global imbalances, notably the large US current account deficit and surpluses elsewhere" (p.1). Obstfeld and Rogoff (2004), for instance, calculate that the correction of the US current imbalance may lead to a real dollar depreciation larger than $20 \%$ with potential serious consequences for real economic activity in the rest of the world. Hence, it is undoubtedly important to analyze the US current account dynamics and adjustment as it has crucial consequences for both the US and global economy.

Our objective in this paper is to analyze the stationarity of the US current account using new econometric tests based on non-linear adjustment that we consider more appropriate to describe the dynamics of the current account. With a few exceptions, ${ }^{2}$ the works previously mentioned have assumed that the adjustment of the current account follows a linear behavior under the alternative of mean reversion. Both statistical evidence and theory arguments challenge this assumption. Our approach has several advantages over previous tests. Firstly, rather than assuming linear adjustment, we test for linearity in the data. If non-linearity is present, then the traditional unit root tests suffer from an important loss of power that may lead to erroneously accepting no-sustainability. Secondly, the tests presented show a richer set of dynamics in the current account that allows us to identify periods of sustainability and no-sustainability and periods in which the current account persistently deviates from its equilibrium (mean) value. Thirdly, by using tests that allow for different speeds of adjustment, we allow for the fact that institutional, preference and policy changes can affect the dynamic adjustment and equilibrium values of the current account. ${ }^{3}$

The paper is organized as follows. In the next Section, we discuss the concept of current account sustainability. In Section 3, we apply a series of non-linearity tests to the US current account. In Section 4, we test for the stationarity of the current account, and Section 5 concludes.

\section{Current account sustainability}

The concept of current account sustainability has been widely discussed in the literature. Mann (2002) considers that sustainability should be viewed both from the

\footnotetext{
${ }^{2}$ See Chortareas et al (2004) for an analysis of debt sustainability in Latin America and Raybaudi et al (2003) for the UK.

${ }^{3}$ See Taylor (2002).
} 
domestic and international finance point of view. A sustainable current account is one that does not trigger feedback effects on domestic variables (investment and savings) or does not lead to significant international portfolio reallocations leading to changes in interest rates. Milessi-Ferretti and Razin (1996) distinguish between solvency and sustainability. An economy is solvent if the expected present value of future trade surpluses equals its current indebtedness. That is, if the economy meets its external intertemporal budget constraint. Sustainability refers to the question of whether the economy is able to meet its budget constraint without a drastic change in private sector behavior or policy shifts. As Milessi-Ferretti and Razin (1996) state, the latter concept has more "structure" as it contains behavioral implications. Nevertheless, the concept of solvency is more general.

In this paper, we will follow Taylor (2002) and use the concept of sustainability as the ability of an economy to satisfy its long-run intertemporal budget constraint. This is a more general concept and does not depend on the particular structural model we have in mind. Also, this concept of sustainability is a sufficient condition for other concepts to hold. An attractive feature of this idea is its testability. As put forward by Trehan and Walsh (1991), current account stationarity is a sufficient condition for the intertemporal budget constraint to hold. Consider a stochastic model with zero growth. The one period budget constraint is,

$C_{t}+I_{t}+G_{t}+B_{t}=Y_{t}+\left(1+r_{t}\right) B_{t-1}$

where $C_{t}, I_{t}, G_{t}, B_{t}$ and $Y_{t}$ are consumption, investment, government consumption, net stock of debt and income respectively. $r_{t}$ is the world interest rate. Rearranging (1) and from national accounts identities we have that,

$B_{t}=\left(1+r_{t}\right) B_{t-1}+N X_{t}$

where $N X_{t}$ is net exports. Iterating (2) forward and assuming that the expected value $E\left(r_{t} \mid \varphi_{t-1}\right)=r$, with $\varphi_{t-1}$ being the information set available in $t-1$, we get

$B_{t}=\sum_{j=0}^{\infty}\left(\frac{1}{1+r}\right)^{j} E\left(N X_{t+j} \mid \varphi_{t-1}\right)+\lim _{T \rightarrow \infty}\left(\frac{1}{1+r}\right)^{T} E\left(B_{t+T} \mid \varphi_{t-1}\right)$ 
Equation (3) simply states that international agents are able to lend to an economy if they expect that the present value of the future stream of net exports surpluses equals the current stock of foreign debt. Hence, the sustainability hypothesis, or long run budget constraint implies that:

$$
\lim _{T \rightarrow \infty}\left(\frac{1}{1+r}\right)^{T} E\left(B_{t+T} \mid \varphi_{t-1}\right)=0
$$

This transversality condition means that the present value of the expected stock of debt when $t$ tends to infinity must equal zero. ${ }^{4}$ Following Trehan and Walsh (1991), given that the current account $C A_{t}=B_{t}-B_{t-1}$, a sufficient condition for (4) to hold is that the current account is a stationary process. ${ }^{6}$ In the more realistic case of an economy with a positive rate of growth of output, we have that the sustainability condition holds if the ratio $y_{t}=\frac{C A_{t}}{Y_{t}}$ is stationary. This means that sustainability is possible with current account deficits as far as they do not grow faster than output in expected value. ${ }^{7}$

An obvious test of sustainability is hence a unit root test on $y_{t}$. This is what most of the literature has previously used as a test of sustainability. However, note that we are dealing here with expected values of future events. Changes in the agents' perceptions about risk, portfolio allocation decisions, future policy changes, transaction costs in international financial flows, etc. can lead to changes in the dynamics of current account mean reversion and hence equilibrium values of the current account. As previously mentioned, Taylor (2002) sees the speed of convergence towards equilibrium as a summary statistic of the degree of capital mobility. This is so because it reflects how long agents are prepared to allow periods of current account deficits (surpluses) above the perceived equilibrium value. If, given the international financial environment, agents' perceptions about, for instance, the relative risk of US dollar denominated assets changes due to large observed current

\footnotetext{
${ }^{4}$ That is, a no-Ponzi game condition.

${ }^{5}$ See also Taylor (2002).

${ }^{6}$ This sustainability condition holds even for the case of a variable real interest rate.

${ }^{7}$ See Trehan and Walsh (1991) for proofs.
} 
account deficits, the speed of mean reversion and the mean of the current account itself would also change. That is, changes in the current account affecting agent's perceptions can trigger adjustment dynamics that are not linear as commonly assummed. In this sense, it may well be the case that tests for stationarity that do not consider the possible non-linear dynamics arising from these effects are mispecified. In that case, we may reach wrong conclusions about the sustainability of the current account or arrive at too simplistic a description of current account dynamics under the hypothesis of stationarity. In the next sections we will test for the existence of nonlinearity in the US current account and, based on these results, use a non-linear unit root test that captures these effects.

\section{Linearity tests}

In the time series literature a commonly used test for the unit root null hypothesis is the well know augmented Dickey-Fuller test (ADF). The test is based on the following regression model:

$$
\Delta y_{t}=\alpha+\beta y_{t-1}+\sum_{j=1}^{k} \delta_{j} \Delta y_{t-j}+\gamma t+\varepsilon_{t} \quad \quad \mathrm{t}=1,2, \ldots . \mathrm{T} .
$$

where $y_{t}$ was previously defined as the ratio of the current account to GDP at time $t$, $\Delta$ is the first difference operator and $\varepsilon_{t}$ is a white noise disturbance term. $t$ is a linear deterministic trend while the $\Delta y_{t-j}$ terms allow for serial correlation and are designed to ensure that $\varepsilon_{t}$ is white noise. The null hypothesis is that $\beta=0$, which corresponds to a unit root in $y_{t}$ (that is, no sustainability). The OLS based $t_{\beta}$ statistic, which does not have a standard normal distribution, can be used to test this hypothesis.

However this test has low power in the presence of non-linear adjustment, leading it to accept very frequently the null hypothesis of a unit root (see Shin and Lee, 2001 and Killian and Taylor, 2003). In other words, as discussed before, the current account data could exhibit some non-linear structure although still stationary. For this reason, if the series presents non-linearities, a proper unit root test must allow for 
asymmetric adjustment under the alternative. ${ }^{8}$ Enders and Granger (1998) reviewed many economic series that confirmed this proposition.

The data used in our analysis is the US quarterly current account to GDP ratio over the period 1960:1-2004:1. We first carried out three linear unit-root tests on the data. These were an ADF test of the null of non-stationarity; the Modified PhillipsPerron test with GLS de-trending $\left(\mathrm{M}_{\alpha}{ }^{\mathrm{GLS}}\right)$ of $\mathrm{Ng}$ and Perron (2001) for the null of a unit root; and Elliott et al's (1996) most powerful DF-GLS test for the null of a unit root. The lag augmentation was chosen using the $\mathrm{Ng}$ and Perron (2001) Modified Information Criteria (MIC). ${ }^{9}$ This method reduces very substantially size distortions. The tests were carried out using a constant term and a constant and a deterministic trend. The results are reported in Table 1. It is easy to see that none of the tests is able to reject the null of a unit root in the current account to GDP ratio of the US.

These findings clearly indicate that current account sustainability cannot be supported, as the unit root hypothesis could not be rejected by the data. However, as noted before, linear tests have low power in the presence of mispecified dynamics leading to the non-rejection of the null hypothesis. Given this problem, we apply various non-linearity tests to investigate if the US current account dynamics are governed by non-linear behaviour. There are a large number of tests developed in the literature for this purpose. Given their different nature, and in order to give a complete picture of the possible nature of non-linearity, we have chosen to use the Ramsey (1969) test, the Keenan (1985) test, the Granger and Teräsvirta (1993) test and the Ludlow and Enders (2000) test.

The Ramsey test - usually referred to as the RESET test - proposed by Ramsey (1969) exploits the idea that if there is non-linearity, then any non-linear transformation of the fitted value of the current account variable $\left(\hat{y}_{t}\right)$ should not be useful in explaining the current value $\left(y_{t}\right)$. The test is based on the following auxiliary regression:

$$
y_{t}=g_{0}+\sum_{j=1}^{p} g_{j} y_{t-j}+\sum_{k=1}^{q} \xi_{k} \hat{y}_{t}^{k+1}+e_{t} \quad \text { for } \quad q \geq 1
$$

\footnotetext{
${ }^{8}$ See for example Caner and Hansen (2001), Shin and Lee (2001) and Enders and Granger (1998).

9 The results using other information methods such as AIC, the Pantula et al. (1994) principle or a general to specific method (GTS) did not change the conclusions about unit-roots.
} 
where $g_{j}$ and $\xi_{k}$ are parameters. An $F$-statistic can be used to test the null hypothesis $H_{0}: \xi_{1}=\ldots=\xi_{q}=0$.

The Keenan (1985) test is based on Tukey's non-additivity test using $\left(\hat{y}_{t}^{2}\right)$ as in the RESET test. Unlike the RESET test, the Keenan test investigates whether $\left(\hat{y}_{t}^{2}\right)$ has any additional forecasting ability for $y_{t}$. To perform this test we have to follow a three step procedure. (a) We estimate a linear equation of the type

$$
y_{t}=g_{1}+\sum_{j}^{k} g_{j} y_{t-j}+e_{t}
$$

and save the residuals $\left(\hat{e}_{t}\right)$ and the fitted values $\left(\hat{y}_{t}\right)$. (b) We regress $\left(\hat{y}_{t}^{2}\right)$ on $\left(y_{t}\right)$ and generate the residuals $\left(\hat{\eta}_{t}\right)$ and (c) we regress $\hat{e}_{t}$ on $\hat{\eta}_{t}$ and obtain the residuals $\hat{v}_{t}$. The test statistic for the null hypothesis of linearity is given by

$$
K=(T-4) \frac{\hat{e}^{\prime} \hat{\eta}\left(\hat{\eta}^{\prime} \hat{\eta}\right)^{-1} \hat{\eta}^{\prime} \hat{e}}{\hat{v}^{\prime} \hat{v}} \quad \rightarrow \chi^{2}(1)
$$

where $\hat{e}, \hat{\eta}, \hat{v}$ are $T \times 1$ vectors of $\hat{e}_{t}, \hat{\eta}_{t}, \hat{v}_{t}$ respectively.

Unlike the RESET and Keenan tests where the rejection of the null hypothesis does not provide a guidance as to the specification of an alternative model Granger and Teräsvirta (1993) suggested a test of the linear null hypothesis against the alternative hypothesis of an exponential smooth transition (ESTAR) model. This approach includes the following artificial regression:

$$
\Delta y_{t}=\beta_{o} y_{t-1}+\sum_{j=1}^{4}\left[\beta_{1 j} y_{t-j} \Delta y_{t-k}^{2}+\beta_{2 j} y_{t-j} \Delta y_{t-k}^{4}\right]+e_{t} \quad \mathrm{t}=1,2, \ldots \ldots \mathrm{T} .
$$

where $e_{t}$ is an error term. The linearity test against an ESTAR consists of testing the null hypothesis $H_{0}: \beta_{1 j}=\beta_{2 j}=0$ for $\mathrm{j}=1,2,3,4$ using the $F$-statistic version of the Lagrange-multiplier test in Teräsvirta (1994). $k$ is a delay parameter that is chosen as the one that maximizes the $F$-statistic for $H_{0}{ }^{10}$

The common feature of all previous parametric tests is that they need to specify the nature of the non-linear coefficient. Thus, the estimated model may suffer from a specification error, which leads very frequently to misguided conclusions. Ludlow

\footnotetext{
${ }^{10}$ In our data we found $k=1$ to be the optimal delay parameter.
} 
and Enders (2000) (LE hereafter) recommend a deterministic time dependent coefficient model without first specifying the nature of non-linearity. To test for nonlinearity following the method proposed by LE we transformed the linear AR(1) model

$\Delta y_{t}=\alpha \Delta y_{t-l}+e_{t} \quad \mathrm{t}=1,2, \ldots . . \mathrm{T}$.

where $\Delta y_{t}$ is a stationary random variable and $e_{t}$ is an error term, as follows:

$\Delta y_{t}=\alpha(t) \Delta y_{t-l}+e_{t}$

where $\alpha(t)$ is a deterministic but unknown function of time.

LE have shown that the function $\alpha(t)$ can be exactly represented by a sufficiently long Fourier series so that,

$\alpha(t)=\mathrm{Z}_{0}+\sum_{k=1}^{s}\left[\mathrm{Z}_{k} \sin \frac{2 \pi k}{T} t+\mathrm{H}_{k} \cos \frac{2 \pi k}{T} t\right]$

where $s$ refers to the number of frequencies contained in the process generating $\alpha(t)$ and $k$ is an integer in the interval 1 to $T / 4^{11} . Z_{k}$ and $H_{k}$ are parameters to estimate.

In order to identify the particular Fourier coefficient we perform the following steps. First, we estimate an AR(p) model in first differences form:

$\Delta y_{t}=\phi_{0}+\sum_{i=1}^{p} \alpha_{i} \Delta y_{t-i}+e_{t}$

The model with the smallest SBC is selected as the best fit model. Next we replace the original series $y_{t}$ by the residual $\hat{e}_{t}$ derived from model (13). Second, for each value of $k$ in the interval 1 to $T / 4$ we estimate:

$\hat{e}_{t}=\left[\mathrm{Z}_{k} \sin \frac{2 \pi k}{T} t+\mathrm{H}_{k} \cos \frac{2 \pi k}{T} t\right] \Delta y_{t-L}$

\footnotetext{
${ }^{11}$ The interval 1 to $T / 4$ refers to quarterly data.
} 
If the incorporation in (14) of the most significant $k^{*}$ does not reduce SBC we terminate the search. Additionally, we use Student's $t$ distribution to test the null hypothesis $\mathrm{Z}_{k}^{*}=0$ and $H_{k}^{*}=0$. Third, having identified the frequency $k^{*}$ and the associated non-zero values $\mathrm{Z}_{k}^{*}$ and $H_{k}^{*}$ we estimate:

$$
\Delta y_{t}=\phi_{0}+\sum_{i=1}^{p} \alpha_{i} \Delta y_{t-i}+\sum_{i=1}^{n}\left[\mathrm{Z}_{k}^{*} \sin \frac{2 \pi k_{i}^{*}}{T} t+\mathrm{H}_{k}^{*} \cos \frac{2 \pi k_{i}^{*}}{T} t\right] \Delta y_{t-L}+\sum_{i=1}^{q} \beta_{i} e_{t-i}+e_{t}
$$

If the value of $Z_{k}^{*}$ or $H_{k}^{*}$ is statistically significant we can conclude that the $y_{t}$ sequence displays asymmetries.

Table 2 presents RESET, Keenan and Granger and Teräsvirta tests for nonlinearity in the data while Table 3 reports the LE tests. The findings in Table 2 show that the US current account presents important non-linearities according to the Keenan and Granger and Teräsvirta non-linearity tests. However, this is not the case for the RESET test which fails to reject the null hypothesis. To examine further the issue of non-linearity we present in Table 3 the results of the LE non-linear test. The traditional $t$-statistics on the $\mathrm{Z}_{k}^{*}$ and $H_{k}^{*}$ parameters show that $\sin$ and $\cos$ terms are statistically significant at conventional levels of statistical significance. This means that the current account in the USA presents important non-linearities. However, since the $t$-distributions for $\sin$ and $\cos$ terms are identical and the regressors are orthogonal LE calculate a single statistic $t^{*}$ based on Monte Carlo simulations. According to these values, which are higher than those of the traditional $t$ distribution, we observe that only a few coefficients remain statistically significant. Nevertheless, LE note that the power of this test depends on the size of $\phi_{0}$ relative to $Z$. Thus, they suggest the analysis of the dynamic behaviour of the time varying coefficient $\alpha(t)$. A close look at the time path of coefficient $\alpha(t)$ shown in Figure 2 reveals that it behaves in a highly non-linear fashion. In particular, in some cases the coefficient $\alpha(t)$ exceeds 0.50 while in others the coefficient is less than -0.50 . This finding is not in line with the results of a linear $\mathrm{AR}(\mathrm{p})$ model where the autoregressive coefficient is assumed constant over time. 
Given the results of the various tests for non-linearity in the US current account dynamics, we can conclude with a certain degree of safety that it follows a non-linear adjustment mechanism. In this case, tests that assume a linear adjustment under the alternative of stationarity would be mispecified. This also confirms that, far from being a constant, the speed of adjustment to the long-run budget constraint is subject to changes and asymmetries.

\section{Unit root tests}

Given the possible existence of non-linearity in time series data, several attempts have been made to develop tests that have better power than the classical ones. Here we will use a test based on the smooth transition family of models. ${ }^{12}$ These models assume that, in our case, the current account balance adjusts to its equilibrium with a different speed depending on whether previous changes in the current account are above or below a threshold. This change of regime is smooth and not radical, and hence takes an adjustment period that is data determined. The existence of this kind of dynamics would be indicative that the current account adjustment reacts to changes in the macroeconomic environment that affect the current account. For instance, for large changes in the current account away from equilibrium we might expect the speed of mean reversion to be faster as markets would not be willing to sustain deviations from equilibrium for a long period. Obviously, this asymmetry of adjustment would also have an impact on the equilibrium value towards which the current account converges.

The unit root test is based on Kapetianos et al (2003) and further developed by Kilic (2003). Kilic (2003) proposed an alternative framework which has a linear nonstationary process under the null against a non-linear stationary alterative, while at the same time is more powerful than the non-linear unit root test proposed by Kapetanios et al. (2003). Given the power of the test, we will use in what follows the Kilic (2003) testing procedure.

\footnotetext{
${ }^{12}$ We also considered the joint asymmetry and unit root test framework in a threshold autoregressive framework (TAR) proposed by Caner and Hansen (2001). Our results showed little evidence of self extracting TAR structure in the US current account. We hence concluded that the non-linearity was not of the kind postulated by this model, i.e. where transition between the different states is immediate. Results are available on request.
} 
Kapetianos et al (2003) and Kilic (2003) consider the following univariate smooth transition AR(1) model

$y_{t}=\rho y_{t-1}+\rho^{*} y_{t-1} \Phi\left[\gamma, \theta ; z_{t}\right]+\varepsilon_{t}$

where $y_{t}$ is stationary ergodic and $\varepsilon_{t} \sim \operatorname{iid}\left(0, \sigma^{2}\right)$. The transition function $\Phi\left[\gamma, \theta ; z_{t}\right]$, allows for non-linear mean reversion in $y_{t}$. Kilic (2003) adopts the exponential transition function,

$\Phi\left[\gamma, \theta ; z_{t}\right]=1-\exp \left[-\gamma\left(z_{t}-\theta\right)^{2}\right]$

where $\gamma(\gamma>0)$ determines the speed of transition between the two extreme regimes, $\theta$ is a threshold value and $z_{t}$ is the transition variable which could be predetermined or exogenous and strictly stationary. In our case, as in many economic applications, we chose $z_{t}=y_{t-k}$ and $k \geq 1$ is an integer denoting the delay parameter.

In this case equation (17) is termed an exponential STAR (ESTAR) model. The ESTAR model accounts for smooth transition between two extreme regimes while it is symmetrically $\mathrm{U}$-shaped around zero. The middle regime corresponds to $y_{t-k}=\theta$, when $\Phi[0]=0$ and equation (17) reduces to the linear AR(1) model

$y_{t}=\rho y_{t-1}+\varepsilon_{t}$

The outer regime corresponds to $\lim _{\left[y_{t-k}-\theta\right] \rightarrow \pm \infty}\left(\Phi\left[\gamma, \theta ; y_{t-k}\right]=1\right)$ so equation (17) becomes a different AR(1) model

$y_{t}=\left(\rho+\rho^{*}\right) y_{t-1}+\varepsilon_{t}$

The AR(1) models in equations (18) and (19) will differ in their speed of mean reversion as long as $\rho^{*} \neq 0$. Re-writing equation (16) as 


$$
\Delta y_{t}=\widetilde{\rho} y_{t-1}+\rho^{*} y_{t-1} \Phi\left[\gamma, \theta ; \Delta y_{t-k}\right]+\sum_{i}^{p} \zeta_{i} \Delta y_{t-i}+\varepsilon_{t}
$$

When $\rho^{*}<0$ and $\widetilde{\rho}+\rho^{*}<0$ then equation (20) describes a process that is locally non-stationary (given the unit root in the linear term) but globally stationary. This indicates that $y_{t}$ locally follows a unit root in the region of $\Delta y_{t-k}=\theta$ $\left(\left[\tilde{\rho}+\rho^{*} \Phi\left(\theta ; y_{t-k}\right)\right]=1\right)$ while large values of $\Delta y_{t-k}$ would result in an approximately $\mathrm{AR}(1)$ process with the stable root $\widetilde{\rho}+\rho^{*}$ provided that $-2<\rho^{*}<0$.

Next, the author imposes $\widetilde{\rho}=0$ in (20) and considers a testing procedure for

$$
\begin{aligned}
& H_{0}: \rho^{*}=0 \\
& H_{0}: \rho^{*}<0,
\end{aligned}
$$

that could be based on $\hat{t}_{\rho^{*}=0}(\gamma, \theta)$. However, since $\gamma$ and $\theta$ are not identified under the null (Davies, 1987) the null hypothesis (21) cannot be tested.

To test directly the null hypothesis (21) Kilic (2003) developed the following $t$ statistic

$\operatorname{Sup}-t=\sup _{(\gamma, \theta) \in \Gamma \times \Theta}\left\{\frac{\hat{\rho}^{*}(\gamma, \theta)}{\text { s.e. }\left(\hat{\rho}^{*}(\gamma, \theta)\right)}\right\}_{\rho^{*}=0}$

where $\Gamma=[\gamma, \bar{\gamma}]$ and $\Theta=[\underline{\theta}, \bar{\theta}]$ are such that $0<\underline{\gamma}<\gamma<\bar{\gamma}$ and $0<\underline{\theta}<\theta<\bar{\theta}$. This corresponds to the values of $\gamma$ and $\theta$ yielding the smallest sum of squared residuals. The value of $\gamma$ is estimated using a grid search method while for the value of $\theta$ the Caner and Hansen (2001) methodology could be adopted ${ }^{13}$. In particular, the possible value of $\theta$ could be selected from the ordered values of $\left|\Delta y_{t-k}\right|$ after having discarded $10 \%$ of the highest and smallest observations. This procedure will guarantee that the boundaries $\underline{\theta}$ and $\bar{\theta}$ do not depend on any unknown parameter.

Based on Monte Carlo simulations, Kilic (2003) concluded that the sup- $t$ has superior power to the ADF and PP tests under the alternative of an ESTAR model. It was also found that the sup $-t$ statistics performs better and is more powerful than the

\footnotetext{
${ }^{13}$ Kilic (2003) notes that we should not make the interval too wide as a very large values of $\gamma$ may make the transition function $\Phi$ become flat.
} 
non-linear ADF test of Kapetanios et al. (2003). Asymptotic critical values for the sup $-t$ are tabulated in Kilic (2003).

Before applying this test we regressed the $y_{t}$ series on a constant and saved the residuals, generating thus a new variable which is de-meaned. Table 4 reports the estimated ESTAR model (16) as well as the unit root test and other diagnostic statistics of the model.

Examination of Table 4 reveals that the sup $-t$ statistic rejects the unit root null hypothesis at the 5\% significance level. This finding is not in line with the results based on linear unit root tests. Hence, as postulated earlier in the paper, assuming a linear behaviour of the mean reversion and equilibrium value of the US current account may drive us to misleading conclusions about its sustainability. In our tests we show that the sufficient condition for the long-run budget constraint to hold is met for the US economy. From the results we can also see that the speed of mean reversion is substantially faster when the current account changes above the threshold, which is consistent with the idea that the AR parameter reflects the degree of capital mobility which, in turn, depends on agents' perceptions about the relative risk of the US economy. The speed of transition between the different regimes appears to be relatively fast. Furthermore, our results show that our ESTAR model is satisfactorily estimated according to the different misspecification tests proposed by Eithheim and Terasvirta (1996). The diagnostic test $F_{L M}$ indicates the absence of serial correlation in the residuals. The $F_{n l}$ test indicates no remaining non-linearity in the model. Finally, the Medeiros and Veiga (2003) test for parameter constancy in non-linear models also indicates that we cannot reject the null of constancy. ${ }^{14}$ Therefore we can conclude that our specification is an adequate model describing the dynamics of the US current account.

Given the flexibility of this model, another advantage that it offers is that it allows us to get further insights into the dynamics of the current account. In particular, we can construct indicators of both the degree of deviation from the mean or equilibrium value and the degree of mean reversion. We follow Taylor and Peel (2000) and measure the importance of misalignments taking into account the sign and size of the

\footnotetext{
${ }^{14}$ See the appendix for details of this test.
} 
deviations ${ }^{15}$ from equilibrium as well as the degree of mean reversion of the current account at a particular point in time using the following transformed transition functions:

$$
\begin{aligned}
& G\left(y_{t-k}\right)=100\left\{\hat{\Phi}\left(\gamma, \theta, y_{t-k}\right\} \operatorname{sgn}\left[y_{t-k}\right]\right. \\
& H\left(y_{t-k}\right)=1-\hat{\Phi}\left[\gamma, \theta ; y_{t-k}\right]
\end{aligned}
$$

where $\operatorname{sgn}\left[y_{t-k}\right]=\frac{y_{t-k}}{\left|y_{t-k}\right|} \cdot G\left(y_{t-k}\right)$ and $H\left(y_{t-k}\right)$ measure deviations from equilibrium and the degree of mean reversion respectively.

Figure 3 contains the plots of the $\hat{\Phi}\left[\gamma, \theta ; y_{t-k}\right], G\left(y_{t-k}\right)$ and $H\left(y_{t-k}\right)$ functions (FUSA, GUSA and HUSA respectively in the graph). First, we observe that the graphs indicate that the duration between two extreme peaks or depressions is short except for the 1981-83 and 1989-91 periods where it lasts several quarters. Therefore we can conclude that the USA current account is characterized by frequent fluctuations showing no persistent dynamics (see upper and lower panel in Figure 3). Second, we identify three periods 1960-1974, 1975-1991 and 1992-2003 of the US recent current account history. The first and the last sub-periods are characterised by very small percentage (positive or negative) deviations of the US current account relative to its equilibrium value. On the other hand, the period 1975-1991 reflects difficulties in controlling the current account deviations (see middle panel in Figure 3). Hence, in general, we find that the 1960-1974 and 1992-2003 periods show both small deviations from equilibrium and rapid mean reversion. The 1974-1992 period is characterised by larger deviations from equilibrium and slower mean reversion. This can be easily related to changes in world macroeconomic environment. The late seventies and eighties were characterised by oil price shocks, debt crises in emerging countries and a strong dollar appreciation in the mid-eighties. Given this environment, agents were prepared to allow larger current account deficits for a longer period of time as the relative risk perception of the US economy improved given the situation elsewhere. This can also be related to agent's expectations of future higher growth

\footnotetext{
${ }^{15}$ Since the transition function measures the importance of the deviation from equilibrium irrespective of the sign and the size, it cannot tell us whether these deviations are positive or negative.
} 
rates in the US and dollar depreciation. This would mean that international financial markets allowed larger current account deficits for longer periods of time as the expected future path of net exports and growth relative to the rest of the world improves. As regards the recent period, we did not find evidence of important current account disequilibria. Nevertheless, in the final period of estimation the reported deviation becomes larger and always negative. We also find evidence of rapid mean reversion dynamics. This may reflect an increasing sensitivity of capital markets to excessive US current account deficits.

\section{Conclusions}

The question of whether or not the US current account follows a sustainable path has gained importance in recent years in both academic and policy debates. In this paper we test whether the dynamics of the US current account are compatible with a long-run intertemporal budget constraint. We take the stationarity of the current account as a sufficient condition for this definition of sustainability. However, we argue that given possible changes in risk perceptions, macroeconomic environment, portfolio allocation decisions, institutional environment, etc., the usual assumption of a linear process for the current account under the alternative hypothesis of stationarity may not be a correct representation.

We tested for non-linear dynamics in the US current account and found substantive evidence of non-linearity according to different tests. We then tested for unit roots by specifying an ESTAR model, which captures adjustment asymmetries and allows us to get further insights about the dynamic adjustment of the US current account for the period 1960:01 to 2004:01. Various diagnostic tests show that the model is a correct specification describing the dynamics of the current account. Our results reject the null hypothesis of no-sustainability of the US current account. That is, the US current account behaves in a non-linear but stationary fashion. Furthermore, our results reveal that only for the period 1974-1992 we can find significant deviations of the current account from equilibrium and a slower speed of mean reversion. The 1960-1974 and 1992-2003 periods show rapid mean reversion and small deviations from equilibrium. 


\section{References}

Caner, M., and B.E. Hansen, 2001, Threshold autoregression with a unit root, Econometrica 69, 1565-1596.

Chortareas, G.E., Kapetanios, G. and Uctum, M., 2004, An investigation of current account solvency in Latin America using non-linear nonstationarity tests, Studies in Nonlinear Dynamics and Econometrics 8, article 4.

Cooper, R.N. 2001, Is the US current account deficit sustainable? Will it be sustained? Brookings Papers in Economic Activity 1, 217-226.

Davies, R.B., 1987, Hypothesis testing when a nuisance parameter is present under the alternative, Biometrika 64, 247-254.

Eithheim, O. and Teräsvirta, T., 1996, Testing the adequacy of smooth transition autoregressive models, Journal of Econometrics 74, 59-75.

Elliott, G., Rothenberg, T. J. and Stock, J.H., 1996, Efficient Tests for an Autoregressive Unit Root, Econometrica 64, 813-836.

Enders, W. and Granger C.W.J., 1998, Unit root tests and asymmetric adjustment with an example using the term structure of interest rates, Journal of Business of Economic and Statistics 16, 304-312

Granger, C.W.J. and Teräsvirta, T., 1993, Modeling Non-Linear Economic Relationships, Oxford University Press, Oxford.

International Monetary Fund, 2004, World Economic Outlook. IMF, Washington DC.

Kapetanios, G, Shin, Y. and Snell, A., 2003, Testing for a unit root in the nonlinear STAR framework, Journal of Econometrics 112, 359-379.

Keenan, K.L, 1985, A Tukey non-additivity type test for time series non-linearity, Biometrica 72, 39-44.

Kilic, R., 2003, A testing procedure for a unit root in the STAR model, Working Paper, School of Economics, Georgia Institute of Technology

Killian, L. and M. Taylor 2003, Why is it difficult to beat the random walk forecast of exchange rates? Journal of International Economics 60, 85-107.

Liu, P. and Tanner, E., 1996, International intertemporal solvency in industrialized countries: evidence and implications, Southern Economic Journal 62, 739-749.

Ludlow, J. and Enders, W., 2000, Estimating non-linear ARMA models using Fourier coefficients, International Journal of Forecasting 16, 333-347.

Mann, C.L., 2002, Perspectives on the US current account deficit and sustainability, Journal of Economic Perspectives 16, 131-152.

McKinnon, R.I., 2001, The international dollar standard and the sustainability of the US current account deficits, Brookings Papers in Economic Activity 1, 227-238.

Medeiros, M.C. and Veiga, A., 2003, Diagnosting checking in a flexible nonlinear time series model, Journal of Time series Analysis 24, 461-482.

Milesi-Ferretti, G.M. and Razin, A., 1996, Sustainability of persistent current account deficits, NBER Working Papers 5467.

$\mathrm{Ng}$, S. and Perron, P., 2001, Lag Length Selection and the Construction of Unit Root Tests with Good Size and Power, Econometrica 69, 1519-1554.

Obstfeld, M. and Rogoff, K., 2004, The unsustainable US current account position revisited. Mimeo, University of California Berkeley.

Otto, G., 1992, Testing a present-value model of the current account: evidence US and Canadian time series, Journal of International Money and Finance 11, 414-430.

Pantula, S.G., Gonzalez-Farias, G. and Fuller, W.A., 1994, A comparison of unit root test criteria, Journal of Business of Economics and Statistics, 12, 449-459 
Ramsey, J.B.1969, Tests for specification errors in classical linear least squares regression analysis, Journal of the Royal Statistical Society B 31, 350-371.

Raybaudi, M. Sola, M. and Spagnolo, F., 2003, Red signals: trade deficits and the current account, CARISMA Brunel University, CTR 19/03.

Shin, D.W. and Lee, O., 2001, Test for asymmetry in possibly nonstationary time series data, Journal of Business and Economic Statistics 19, 233-244.

Taylor, A.M., 2002, A century of current account dynamics, Journal of International Money and Finance 21, 725-748.

Taylor, M. and Peel, D., 2000, Nonlinear adjustment, long-run equilibrium and exchange rate fundamentals, Journal of International Money and Finance 19, 33-53.

Teräsvirta, T., 1994, Specification, estimation and evaluation of smooth transition autoregressive models, Journal of the American Statistical Association 89, 208-218.

Trehan, B. and Walsh, C., 1991, Testing intertemporal budget constraints: theory and applications to US federal budget deficits and current account deficits, Journal of Money, Credit and Banking 26, 206-223.

Ventura, J. 2001, A portfolio view of the US current account deficit, Brookings Papers in Economic Activity 1, 239-252.

Wickens, M.R. and Uctum, M., 1993, The sustainability of current account deficits: a test of the US intertemporal budget constraint, Journal of Economic Dynamics and Control 17, 423-441.

$\mathrm{Wu}, \mathrm{J}-\mathrm{L} ., 2$ 2000, Mean reversion of the current account: evidence from the panel data unit root test, Economics Letters 66, 219-224. 
Figure 1: US Current Account to GDP Ratio 1960-2004 (\%)

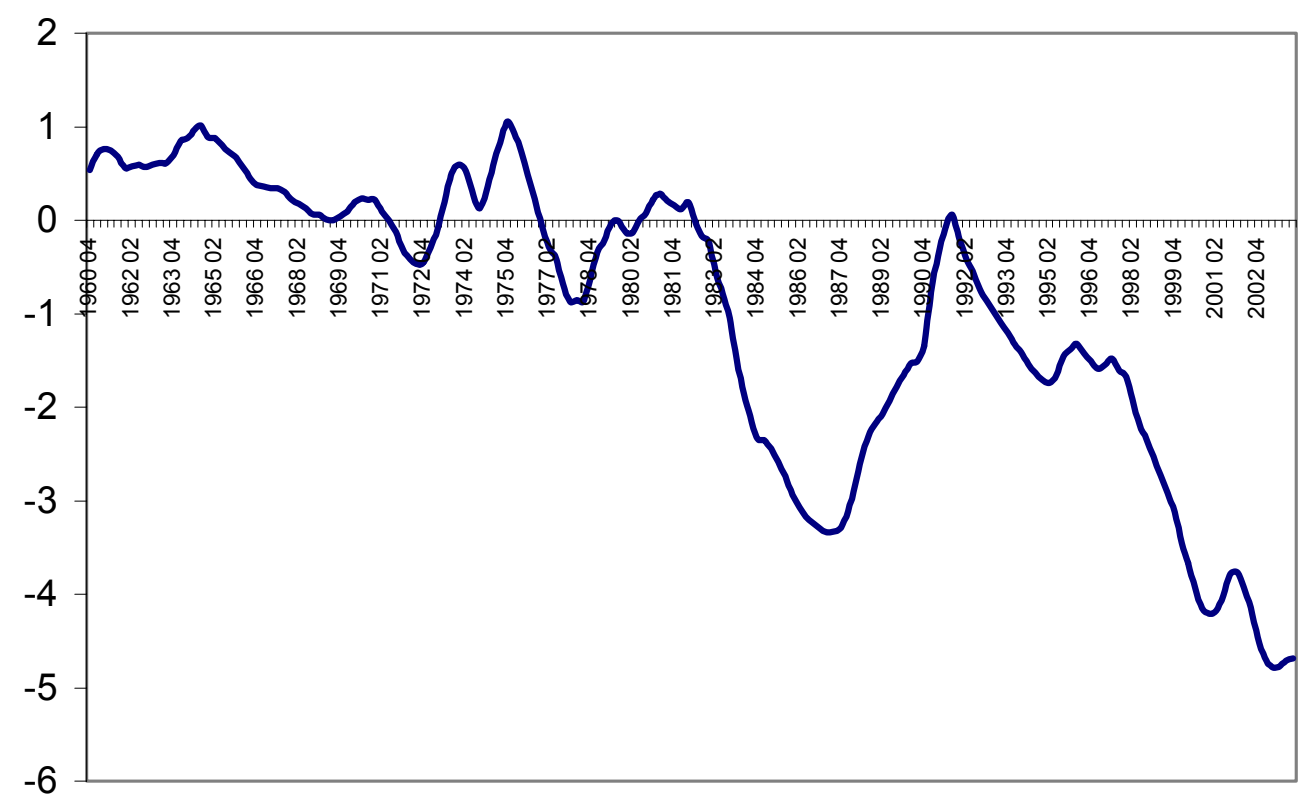


Figure 2: The $A R(1)$ coefficient over time

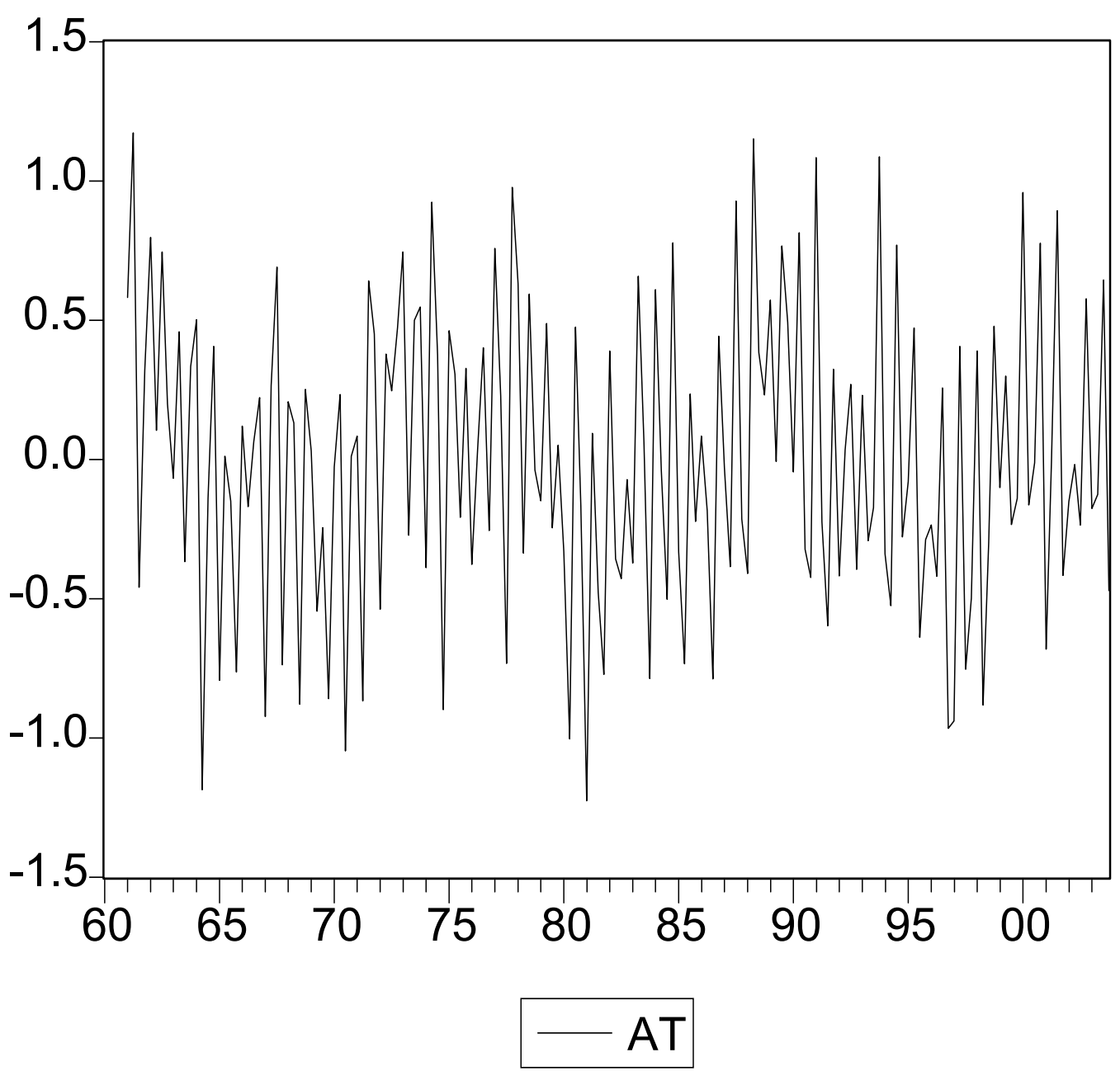


Figure 3: Mean- reversion dynamics and degree of misalignment
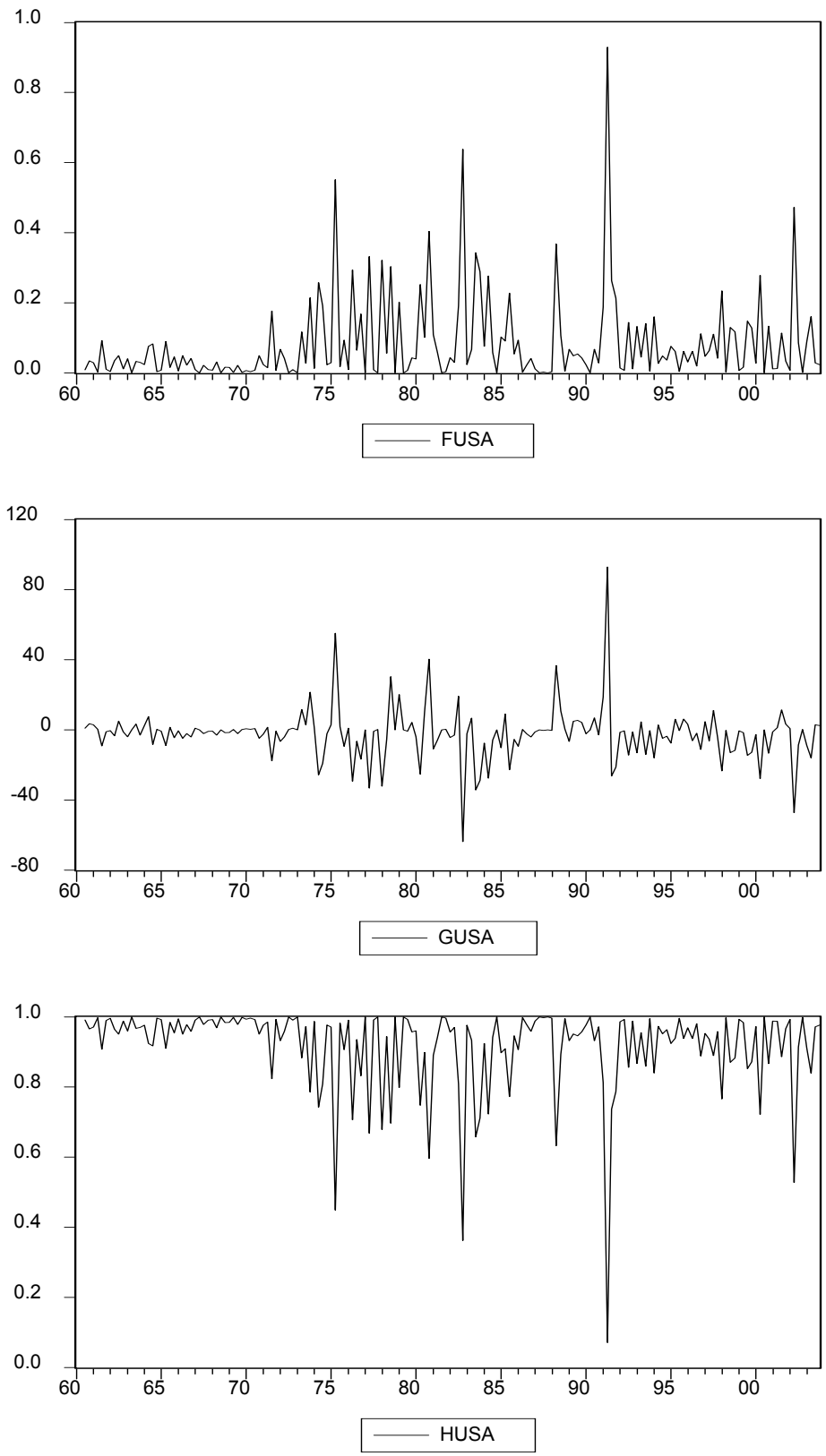
Tables

Table 1: Linear unit root tests.

\begin{tabular}{|l|c|c|c|}
\hline & ADF & $\mathrm{M}_{\alpha}{ }^{\text {GLS }}$ & ERS DFGLS \\
\hline Constant & -0.24 & 0.40 & 0.38 \\
\hline Constant and trend & -2.05 & -1.69 & -1.73 \\
\hline
\end{tabular}

Notes: the $5 \%$ critical values for the $A D F, M_{\alpha}^{G L S}$ and DF-GLS tests are -2.86, -1.98 and -1.98 for the constant only case respectively. For the constant and trend case these are $-3.41,-2.91$ and -2.91 .

Table 2: Tests for non-linearity in the data.

\begin{tabular}{|ll|c|c|}
\hline \multicolumn{2}{|c|}{ RESET- $p$-values } & Keenan $x^{2}$ test & Granger and Teräsvirta $p$-values \\
\hline$k=1$ & 0.43 & $\mathbf{3 4 . 5 2}$ & $\mathbf{0 . 0 5}$ \\
\hline$k=2$ & 0.16 & & \\
\hline$k=4$ & 0.45 & & \\
\hline
\end{tabular}

Note: The critical value for the Keenan $x^{2}$ test is 6.63. Bold values indicate rejection of the null hypothesis at 5\% significance level. 
Table 3: Estimates of Fourier model (15).

\begin{tabular}{|c|c|c|}
\hline Parameters & Coefficients & $t-$ ratios \\
\hline$\phi_{0}$ & 0.001 & 0.068 \\
\hline$y_{t-1}$ & -0.047 & -0.065 \\
\hline$y_{t-2}$ & -0.349 & -0.579 \\
\hline$y_{t-3}$ & 1.027 & 1.595 \\
\hline$Z_{k}^{*} * \Delta y_{t-1}$ & $\begin{array}{ll}k=33 & k=62 \\
0.260 & -0.343\end{array}$ & $\begin{array}{r}k=33 \\
2.474 * *\end{array}$ \\
\hline$Z_{k}^{*} * \Delta y_{t-2}$ & $\begin{array}{ll}k=8 & k=33 \\
0.260 & -0.261\end{array}$ & $\begin{array}{cc}k=8 & k=33 \\
2.278^{* *} & -2.51^{* *}\end{array}$ \\
\hline$Z_{k}^{*} * \Delta y_{t-3}$ & $\begin{array}{cc}k=33 & k=62 \\
-0.293 & -0.462 \\
\end{array}$ & $\begin{array}{ll}k=33 & k=62 \\
2.270^{* *} & -4.298 * *\end{array}$ \\
\hline$H_{k}^{*} * \Delta y_{t-1}$ & $\begin{array}{l}k=3 \\
0.232\end{array}$ & $\begin{array}{l}k=3 \\
2.232 * *\end{array}$ \\
\hline$H_{k}^{*} * y_{t-2}$ & $\begin{array}{l}k=49 \\
-0.293\end{array}$ & $\begin{array}{l}k=49 \\
-\mathbf{2 . 9 5 8 * *}\end{array}$ \\
\hline$H_{k}^{*} * y_{t-3}$ & & \\
\hline
\end{tabular}

Note: We estimated firstly an ARMA(p) model and used the SBC to find which model fits best the data.. We chose an ARMA(3) model. Figures in brackets indicate absolute t-ratios. Diagnostic statistics (normality and autocorrelation) for the ARMA(3) model were also performed. According to these results the ARMA(3) model seems to be free from specification errors. (**) indicates statistical significance at the $5 \%$ statistical level. Bold values denote statistical significance using the two sided $t^{*}$ test. The critical $t^{*}$ value for $Z_{k}^{*}$ or $H_{k}^{*}$ is taken from LE (Table 1) and it is 2.83 at the $5 \%$ level. $k$ stands for the most important frequencies in the interval 1 to $T / 4$. 
Table 4: Non-linear sup $-t$ unit root test and estimated ESTAR model

\begin{tabular}{|c|c|c|}
\hline Variables & Coefficients & $p$-values \\
\hline$\zeta_{1}$ & 0.14 & 0.08 \\
\hline$\zeta_{2}$ & -0.03 & 0.72 \\
\hline$\zeta_{3}$ & 0.12 & 0.10 \\
\hline$\rho^{*}$ & -0.18 & \\
\hline$\hat{\gamma}$ & 0.10 & \\
\hline$\hat{\theta}$ & 0.011 & \\
\hline & & \\
\hline sup-t & $-1.68^{*}$ & \\
\hline$F_{L M}$ & 0.35 & \\
\hline$F_{n l}$ & 0.82 & \\
\hline$L M_{P S}$ & 4.79 & \\
\hline
\end{tabular}

Notes: The number of coefficients $\left(\zeta_{1}-\zeta_{3}\right)$ was selected by regressing $\Delta y_{t}$ on its lagged values. The optimal highest lags were obtained by using Schwarz criterion. The delay parameter $\Delta y_{t-k}$ is equal to one and was selected by minimizing the squared residuals of corresponding regression. Since $\hat{\gamma}$ and $\hat{\theta}$ were obtained through a grid search method, the have no $p$-values. The critical value for sup-t test for 100 observations is -1.53 at 5\% statistical level. The $\hat{\gamma}$ was normalised by the sample variance of the transition variable, so as to make $\hat{\gamma}$ approximately scale free. If we remove the standardization we obtain a value for the $\hat{\gamma}$ equal to 16.03. $F_{L M}$ denotes the Eithheim and Terasvirta (1996) $F$-statistic of serial dependence. The $F_{n l}$ test represents the Eithheim and Terasvirta (1996) test for the null hypothesis that there is no remaining non linearities. The $L M_{P S}$ test is the Medeiros and Veiga (2003) LM test for parameter constancy and is distributed as a $\chi^{2}(4)$ [see Appendix for details]. An (*) indicates rejection of the unit root hypothesis at 5\% statistical level. 


\section{Appendix}

To check for parameter constancy we adopt a recently suggested test by Medeiros and Veiga (2003). This test is fully parametric and allows the parameters to change smoothly as a function of time under the alternative hypothesis. We write our nonlinear model as follows:

$y_{t}=G\left(\mathbf{X}_{t}, \mathbf{Z}_{t} ; \boldsymbol{\Psi}\right)+\varepsilon_{t}=\boldsymbol{\beta}^{\prime} \mathbf{X}_{\mathbf{t}}+\xi^{\prime} \mathbf{X}_{\mathbf{t}} \Phi\left[\gamma, \theta ; \mathbf{Z}_{\mathbf{t}}\right]+\varepsilon_{t}$

where $X_{t}$ is a $p \times 1$ vector of lagged values of $y_{t}$, the function $\Phi\left[\gamma, \theta ; \mathbf{Z}_{\mathbf{t}}\right]$ is the exponential function, $Z_{t}$ is a $q \times 1$ vector of transition variables and $\gamma$ and $\theta$ are parameters.

Next, we consider that $\beta$ and $\xi$ are time variant parameters that is $\beta_{t}=\beta^{\prime}(t)$ and $\xi_{t}=\xi^{\prime}(t)$ and they are given by

$$
\begin{aligned}
& \beta(t)=\beta+\sum_{j=1}^{B} \widetilde{\beta}_{j} \Phi\left(\varsigma_{j}\left(t-h_{j}\right)\right) \\
& \xi(t)=\xi+\sum_{j=1}^{B} \widetilde{\xi}_{j} \Phi\left(\varsigma_{j}\left(t-h_{j}\right)\right)
\end{aligned}
$$

In order to ensure the identifiably of the model we have to impose the restrictions: $h_{1} \leq h_{2} \leq \ldots . h_{B}$ and $\xi_{j}>0, j=1,2,3, \ldots . . B . h_{B}$ and $\xi_{j}$ are parameters. When $\xi_{j} \rightarrow \infty$ equations A2 and A3 constitute a model with $B$ structural breaks. Using expressions A2 and A3 and considering that $B=1$ the model A1 can be written as follows:

$$
y_{t}=\left\{\beta^{\prime}+\widetilde{\boldsymbol{\beta}} \Phi\left(\varsigma\left(t-h_{j}\right)\right)\right\} X_{t}+\left\{\xi^{\prime}+\xi \Phi\left(\varsigma\left(t-h_{j}\right)\right)\right\} X_{t} \Phi\left[\gamma, \theta ; Z_{t}\right]+\varepsilon_{t}
$$

The null hypothesis of parameter constancy is $H_{0}: \varsigma=0$. Since $\varsigma$ is not identified under the null hypothesis we have to adopt the following procedure. In particular, we expand $\Phi(\varsigma(t-h))$ into a first-order Taylor expansion around $\varsigma=0$. It is given by 
$t_{1}=0.25 \varsigma(t-h)+\mathrm{H}(t ; \varsigma, h)$

where $\mathrm{H}(t ; \varsigma, h)$ is the remainder. Replacing $\Phi(\varsigma(t-h))$ in A4 by A5 we have

$y_{t}=\left(\mathbf{i}_{\mathbf{0}}^{\prime}+\boldsymbol{\mu}_{\mathbf{0}}^{\prime} t\right) \mathbf{X}_{\mathbf{t}}+(\mathbf{l}+\boldsymbol{\mu} t) \mathbf{X}_{t} \Phi\left[\gamma, \theta ; Z_{t}\right]+\varepsilon_{t}$

where $\mathbf{t}_{0}=\boldsymbol{\beta}-\widetilde{\boldsymbol{\beta}} h / 4, \boldsymbol{\mu}_{0}=\widetilde{\boldsymbol{\beta}} / 4, \mathbf{\imath}=\xi-\xi h / 4$ and $\boldsymbol{\mu}=\widetilde{\xi} / 4$.

Now the null hypothesis is

$H_{0}=\mu_{0}=\mu=0$

It is now easy to obtain the log likelihood function in the nationhood of $H_{0}$ for observation $t$ and ignoring the remainder $\mathrm{H}(t ; \varsigma, h)$ as

$l_{t}=-0.5 \ln (2 \pi)-0.5 \ln \sigma^{2}-\frac{1}{2 \sigma^{2}}\left\{y_{t}-\left(i_{0}^{\prime}+\mu_{0}^{\prime} t\right) X_{t}-\left(i^{\prime}-\mu^{\prime}\right) X_{t} \Phi\left[\gamma, \theta ; Z_{t}\right]\right\}^{2}(\mathrm{~A} 8)$

The $L M$ test can be written as follows

$L M=\frac{1}{\hat{\sigma}^{2}} \sum_{t=1}^{T} \hat{\varepsilon}_{t} v_{t}^{\prime}\left\{\sum_{t=1}^{T} \hat{v}_{t} \hat{v}_{t}^{\prime}-\sum_{t=1}^{T} \hat{v}_{t} \hat{g}_{t}^{\prime}\left(\sum_{t=1}^{T} \hat{g}_{t} \hat{g}_{t}^{\prime}\right)^{-1} \sum_{t=1}^{T} \hat{g}_{t} \hat{v}_{t}^{\prime}\right\} \sum_{t=1}^{T} \hat{v}_{t} \hat{\varepsilon}_{t}$

where $\hat{g}_{t}=\nabla G\left(X_{t}, Z_{t} ; \hat{\Psi}\right)$ and $\hat{v}_{t}=\left[t X_{t}^{\prime}, t X_{t}^{\prime} \hat{\Phi}\left(\gamma, \theta ; Z_{t}\right]^{\prime}\right.$. Under the null hypothesis Medeiros and Veiga (2003) have shown that A9 is distributed as $\chi^{2}(m)$ statistic with $m=(h+1)(p+1)$. In our application we consider only the case of $h=1$. 